\title{
Arctic sea-ice albedo derived from RGPS-based ice-thickness estimates
}

\author{
R.W. LiNDSAY \\ Polar Science Center, Applied Physics Laboratory, University of Washington, Seattle, WA 98095, U.S.A.
}

\begin{abstract}
The RADARSAT geophysical processor system (RGPS) uses sequential synthetic aperture radar images of Arctic sea ice taken every 3 days to track a large set of Lagrangian points over the winter and spring seasons. The points are the vertices of cells, which are initially square and $10 \mathrm{~km}$ on a side, and the changes in the area of these cells due to opening and closing of the ice are used to estimate the fractional area of a set of first-year ice categories. The thickness of each category is estimated by the RGPS from an empirical relationship between ice thickness and the freezing degree-days since the formation of the ice. With a parameterization of the albedo based on the ice thickness, the albedo may be estimated from the first-year ice distribution. We compute the albedo for the first spring processed by the RGPS, the early spring of 1997. The data include most of the Beaufort and Chukchi Seas. We find that the mean albedo is 0.79 with a standard deviation of 0.04 , with lower albedo values near the edge of the perennial ice zone. The biggest source of error is likely the assumed rate of snow accumulation on new ice.
\end{abstract}

\section{INTRODUGTION}

The albedo of Arctic pack ice is a highly significant factor for establishing the energy balance of the ice. The net solar radiation absorbed at the surface is one of the largest terms in estimates of the spring energy balance (Maykut, 1982) and has a profound effect on the mean ice thickness predicted by numerical simulations. Ebert and Curry (1993) performed a number of sensitivity studies with their ice model and found, for example, that the model equilibrium ice thickness changed by $0.6 \mathrm{~m}$ for only a $2 \%$ change in the net solar flux at the surface. This change could be provided by just a 0.01 change in the mean albedo if the mean albedo is 0.50. Also, Shine and Henderson-Sellers (1985) found in their numerical model that increasing the melting-snow albedo from 0.65 to 0.70 increased the estimated mean ice thickness by about $1 \mathrm{~m}$.

While the albedo of the ice surface has long been recognized as a key element of the surface heat balance, extensive measurements of its value over large areas are few and far between (e.g. Grenfell and Perovich, 1984; Allison and others, 1993; Brandt and others, 1999). Because in situ measurements of surface albedo are made at isolated points, the areal distribution of ice of various types needs to be determined to estimate the areal average. Areal-average albedo measurements can be made from aircraft or satellite visible-channel images, but aircraft measurements are restricted in spatial and temporal coverage, and satellite retrievals suffer from a number of other weaknesses. Lindsay and Rothrock (1994) outlined a five-step process that is the basis, in one form or another, for most visible-channel albedo algorithms in use. The steps include cloud masking, instrument calibration, atmospheric corrections (including the effects of ozone, water vapor and aerosols), a correction for the bidirectional reflectance of the surface, and finally the conversion from narrowband to broadband albedo. After all of these corrections, the remain- ing uncertainty is estimated at $0.05-0.10$. It is important to realize that this uncertainty assumes that clouds have been properly masked. Uncertainty in cloud-masking procedures can add substantially to the albedo uncertainty, and the cloud masking should be considered part of the albedo-estimation procedures. Two recent analyses of Arctic-wide, temporally varying albedo estimates utilized satellite imagery from the Defense Meteorological Satellite Program (DMSP) Operational Linescan System (OLS) (Robinson and others, 1992) and from the U.S. National Oceanic and Atmospheric Administration (NOAA) Advanced Very High Resolution Radiometer (AVHRR) as interpreted by the International Satellite Cloud Climatology Project (ISCCP) (Rossow and Schiffer, 1991). Schweiger and others (1993) compared these analyses and found that although the spatial patterns of the surface albedo were in general agreement, the ISCGP values were systematically lower than the OLS values by about 0.10 .

We offer a new way to estimate the albedo based on the firstyear ice-thickness distributions estimated by the RADARSAT geophysical processor system (RGPS). The RGPS is designed to take calibrated and geo-located RADARSAT images, which have a resolution of $100 \mathrm{~m}$, and track a large number of points in a Lagrangian fashion, i.e. the same points on the ice are tracked from image to image for an extended period of time to form Lagrangian trajectories (Kwok and others, 1995; Kwok, 1998). The locations of the points are initially established on a uniform grid. One of the products of the RGPS is the first-year ice-thickness distribution based on the history of the deformation of four-cornered cells. In our method, the albedo of the cell is then determined from the thickness distribution, a climatological snow-accumulation rate and a parameterization of the albedo.

This technique may provide an estimate of the surface albedo that is as good as or better than that obtained by other satellite-based methods and has the advantage of being independent of cloud cover. A rough estimate of the uncertainty is 

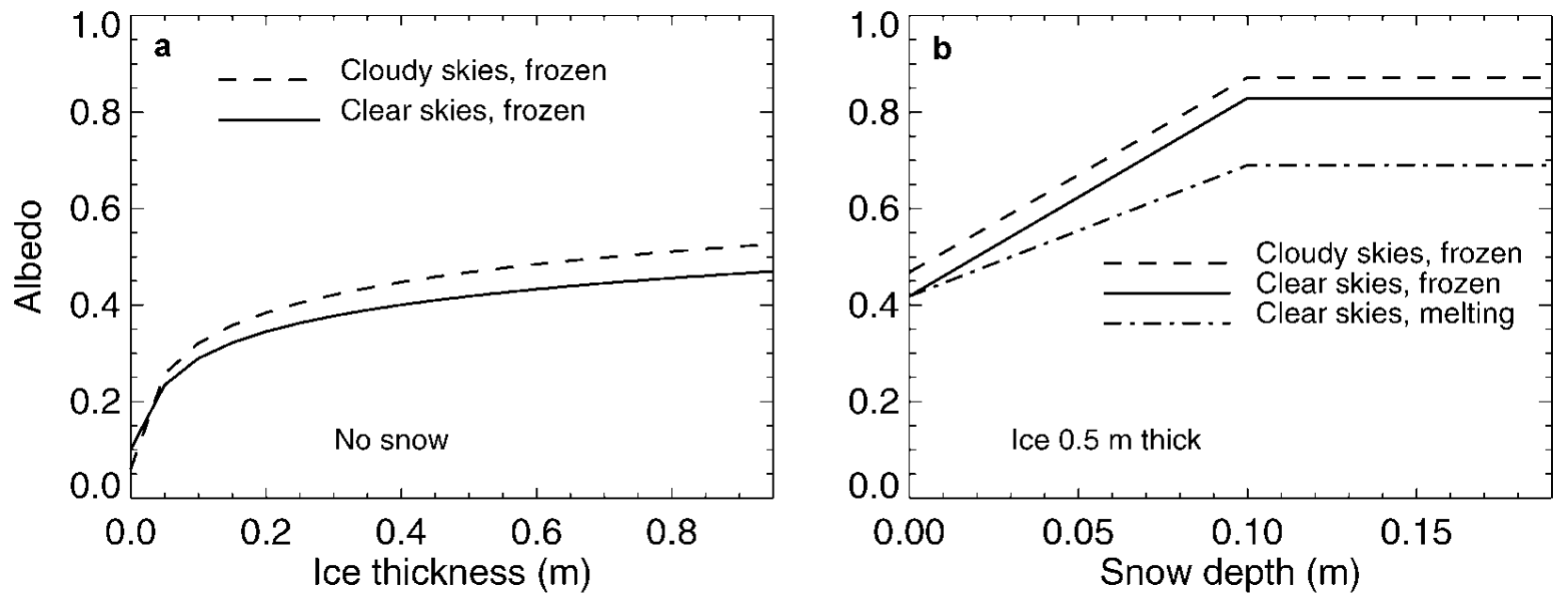

Fig. 1. Broadband albedo parameterization based on Ebert and Curry (1993): (a) for bare ice as a function of ice thickness; (b) for ice $0.5 \mathrm{~m}$ thick as a function of snow depth. The clear-sky cases are for a solar zenith angle of $70^{\circ}$.

found by taking a weighted average of the uncertainties in the parameterized values. If, for example, the uncertainty is 0.05 for thick snow-covered ice which covers about $90 \%$ of the area, and about 0.20 for thin ice which covers the remaining $10 \%$, the weighted average is 0.07 . This is comparable to the uncertainty of about $0.05-0.10$ in the AVHRR determination of the albedo using properly cloud-masked images. The largest single factor in determining the aggregate albedo in the spring is the fraction of thin ice, and this factor is well estimated by the RGPS.

The purpose of this paper is to outline the method and show some preliminary results based on the first spring season processed by RGPS. We will first outline the albedo parameterization, discuss the method for estimating the snow cover and review the RGPS data products. Then we will show results for the spring of 1997 for the Beaufort and Chukchi Seas through 21 April, the last date currently available.

\section{METHODS}

\section{Albedo algorithm}

The albedo algorithm we use is based on the Ebert and Curry (1993) albedo parameterization. The model includes five surface types (dry snow, melting snow, bare ice, meltwater ponds and open water) and four spectral bands. Both direct and diffuse albedos are included for dry snow and open water because the direct albedos for these surface types depend significantly on the solar zenith angle. Only diffuse albedo is included for the other surface types. The arealaveraged albedo is then a function of the surface types present, the cloud cover, the solar zenith angle, the ice thickness and the snow depth. Each RGPS ice-thickness class must be assigned a surface type based on the temperature, snow depth and ice thickness.

We use a snow-depth climatology based on observations from the drifting ice camps of the former Soviet Union, as were analyzed by Warren and others (1999). The accumulation rate is determined from changes in the climatological snow depths based on location and time of year. Each of the first-year thickness classes determined by RGPS has an age associated with it, so that the snow depth for any given class is simply the net climatological accumulation since the ice was formed. The accumulation rates in the spring are quite low, amounting to only $2 \mathrm{~cm} \mathrm{month}^{-1}$, while in the fall they are near $10 \mathrm{~cm} m o n t h^{-1}$. Total accumulation for the fall through spring seasons is $30-40 \mathrm{~cm}$. The age of the thin-ice categories in our data ranges up to 160 days. These oldest categories have an estimated ice thickness of $1.6 \mathrm{~m}$ and a snow depth of $20 \mathrm{~cm}$. For lack of better information, we assume ridged ice accumulates snow at the same rate as smooth ice.

The four spectral bands in the Ebert and Curry algorithm are $0.25-0.69,0.69-1.19,1.19-2.38$ and $2.38-4.00 \mu \mathrm{m}$. In order to determine the broadband albedo, we must average these four bands with appropriate spectral weighting, which is determined with the radiative transfer program Streamer (Key and Schweiger, 1998). Two sets of weights were determined, one for clear skies and one for cloudy skies. For clear skies the weights are $0.500,0.346,0.144$ and 0.010 , and for cloudy skies they are $0.582,0.343,0.074$ and 0.0002 (personal communication from J. Key, 2000). The parameterized values of the broadband albedo as a function of ice thickness, snow depth, cloud state and surface state are shown in Figure 1. Here we treat ridged ice and smooth ice the same, although if we had information about how the albedos differed, they could be treated separately. Since the albedo is a function not only of the surface conditions, but also of the cloudiness and the solar zenith angle, we adopt the convention of reporting the values for clear skies and a solar zenith angle of $70^{\circ}$.

\section{RGPS processing}

The RGPS was developed and is operated by the Polar Remote Sensing group at the Jet Propulsion Laboratory in Pasadena, CA. In the RGPS processing, the trajectories are grouped into four-cornered cells, initially square, which are followed for the season, beginning in the fall. The initial spacing of the points is $10 \mathrm{~km}$, and the typical interval between observations is 3 days. The coastal zones were initialized with larger $25 \mathrm{~km}$ spacing because of the difficulty in tracking the ice in regions of high deformation. The tracking error is $100-300 \mathrm{~m}$. An age distribution is developed for each cell during the winter months in the following manner: when a cell expands (during opening, or divergence), an age category is born and its area is equal to the areal increase in the cell; when a cell contracts (during closing, or convergence), the ice in the thinnest categories is transferred into new ridged-ice categories. 

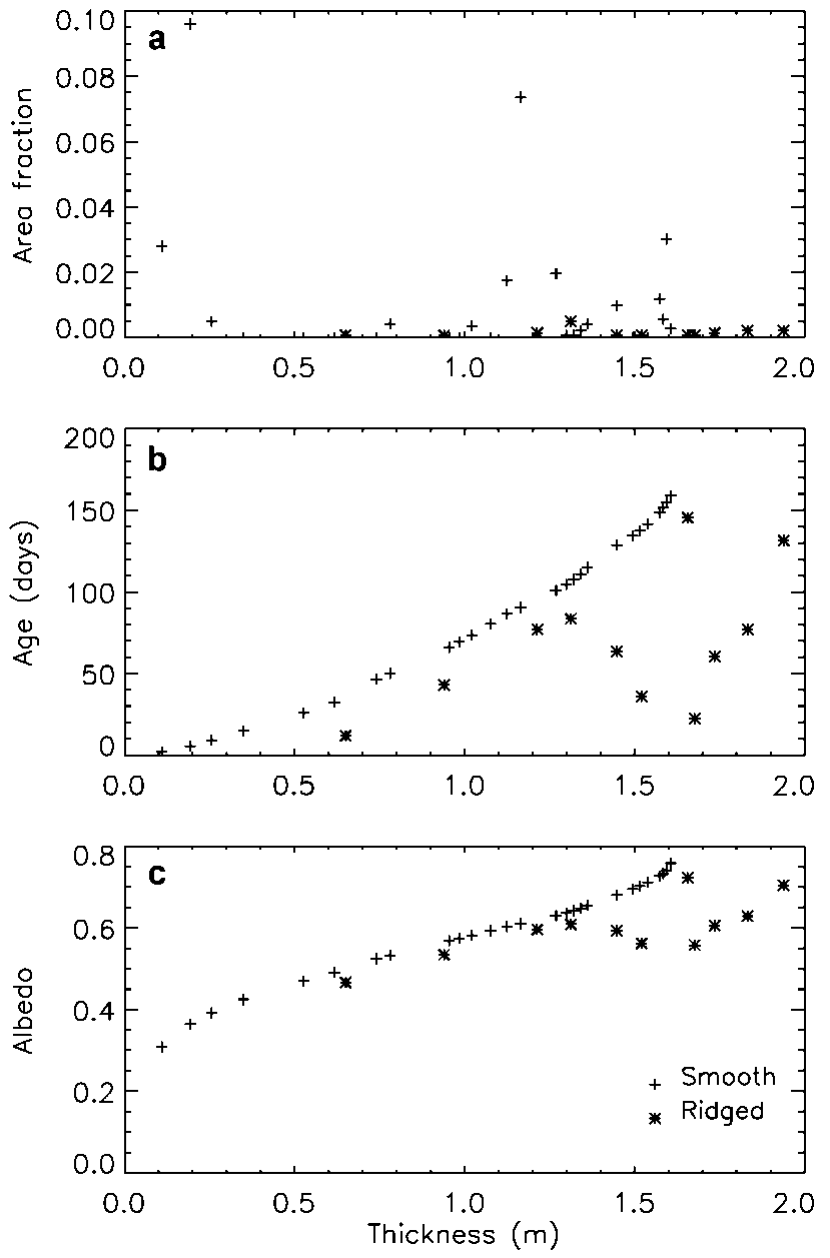

Fig. 2. Illustration of the albedo-estimation procedure for one cell at $77.7^{\circ} \mathcal{N}, 167.2^{\circ} \mathrm{E}$ on 18 April 1997 after 155 days of tracking. (a) Area fraction of each ice category vs ice thickness. (b) Age of each category vs ice thickness. (c) Estimated albedo of each category os ice thickness. This cell had a smooth-ice fraction (all ages) of 0.31, a ridged-ice fraction of 0.019 and $a$ mean albedo of 0.70 .

A thickness distribution is obtained from the age distribution for each cell using a relationship developed by Lebedev (discussed by Maykut, 1986) to determine the thickness. This relationship, $h=1.33 \mathrm{FDD}^{0.58}$, where FDD is the freezing degree-days $\left({ }^{\circ} \mathrm{C}\right)$ and $h$ is in centimeters, is empirically derived from observations made mostly in the (then) Soviet Arctic. The surface air temperature used to determine the number of freezing degree-days experienced by each age category is from the buoy-derived Polar Exchange at the Sea SurfaceInternational Arctic Buoy Program (POLES-IABP) temperature fields (Rigor and others, 2000).

Ridged ice is assigned a thickness five times the thickness of the ice that was ridged and occupies one-quarter of the area. In the RGPS, all of the ice in the thinnest category is consumed before ice in the next-thickest category is ridged. The age and thickness calculations are stopped in the late spring when the ice thickness is no longer closely related to the ice age and FDD. The web site for the RGPS is wwwradar.jpl.nasa.gov/rgps/radarsat.html, where the data are available for downloading.

The RGPS now produces four data products grouped by month: Lagrangian ice motion (individual trajectories), ice deformation (fundamental cell statistics for each cell at each observation), ice-age and ice-thickness histograms (cumula- tive since the beginning of the season) and radar backscatter histograms. The observation times are highly irregular, with roughly one-third of the 40000 cells reporting an observation during any one day. Occasionally trajectories go for $>15$ days without an observation, and these are no longer tracked and their cells are no longer maintained. Some cells become so highly distorted that the computed area becomes near zero or even negative. We exclude from our analysis these small cells $\left(<20 \mathrm{~km}^{2}\right)$, those whose area becomes very large $\left(>200 \mathrm{~km}^{2}\right)$, those that began as large cells near the coast, and those that do not have an observation within 15 days of the final observations.

For the data we analyzed, the season began on 7 November 1996 and the ice was tracked through 21 April 1997, so that ample time had elapsed for the cells to establish the first-year ice-thickness distribution. Our processing procedure selects the final observation from cells that meet the above criteria (22 992 cells, $2.4 \times 10^{6} \mathrm{~km}^{2}$ ), determines the snow depth from snow-accumulation-rate climatology, computes the albedo for each thickness class, and finally determines the mean albedo of the cell as the area-weighted average.

\section{RESULTS}

As an example, Figure 2 shows the area fraction, the age and the albedo of each ice-thickness category vs the ice thickness for a single cell. The increase in the thickness with age is apparent, as well as the increase in the albedo. The mean albedo for all the cells was 0.79 with a standard deviation of 0.04 , indicating that the deformation did not produce large variations in the mean albedo for these cells. The minimum albedo was 0.35 and occurred in a cell with a large amount of opening shortly before the end of the observation period. The standard deviation of the albedo within cells ranged up to 0.29 and averaged 0.08 , indicating that the thin ice creates significant variability within the cells.

The albedo for all cells on 20 April 1997 is shown on the map in Figure 3. Each cell is plotted with its actual shape, so cells that have experienced extensive stretching, either from divergence or from shear, appear elongated and often show low albedo values. Note that while the spatial coverage is excellent over much of the Beaufort and Chukchi Seas, there are significant gaps, mostly along the coast and in the southern regions. The seasonal ice zone was not tracked in the initial release of the RGPS products, since there was no ice to track in those regions at the time the trajectories were initialized at the beginning of November 1996. These regions will be tracked, with later initialization times, in the future. The increased deformation in the ice near the southern limit of the perennial ice zone, particularly in the East Siberian Sea, is reflected in the marked decrease in the albedo estimated for these regions. The zonal mean albedo decreases from 0.80 at $80^{\circ} \mathrm{N}$ to 0.75 at $73^{\circ} \mathrm{N}$. The standard deviation of the mean albedo of the cells also increases to the south, from 0.02 at $80^{\circ} \mathrm{N}$ to 0.06 at $73^{\circ} \mathrm{N}$. A few lines of enhanced deformation (slip lines) are manifest as lines of lower albedo.

Figure 4 shows the cumulative distribution of the ice thickness and of the mean albedo of the cells. The ice-thickness distribution includes both smooth first-year ice and ridged ice. There is no open water, since the RGPS thickness-estimation procedure immediately converts any open areas to thin ice, using the average FDD over the most recent observation interval. The albedo distribution shows that the dominant 


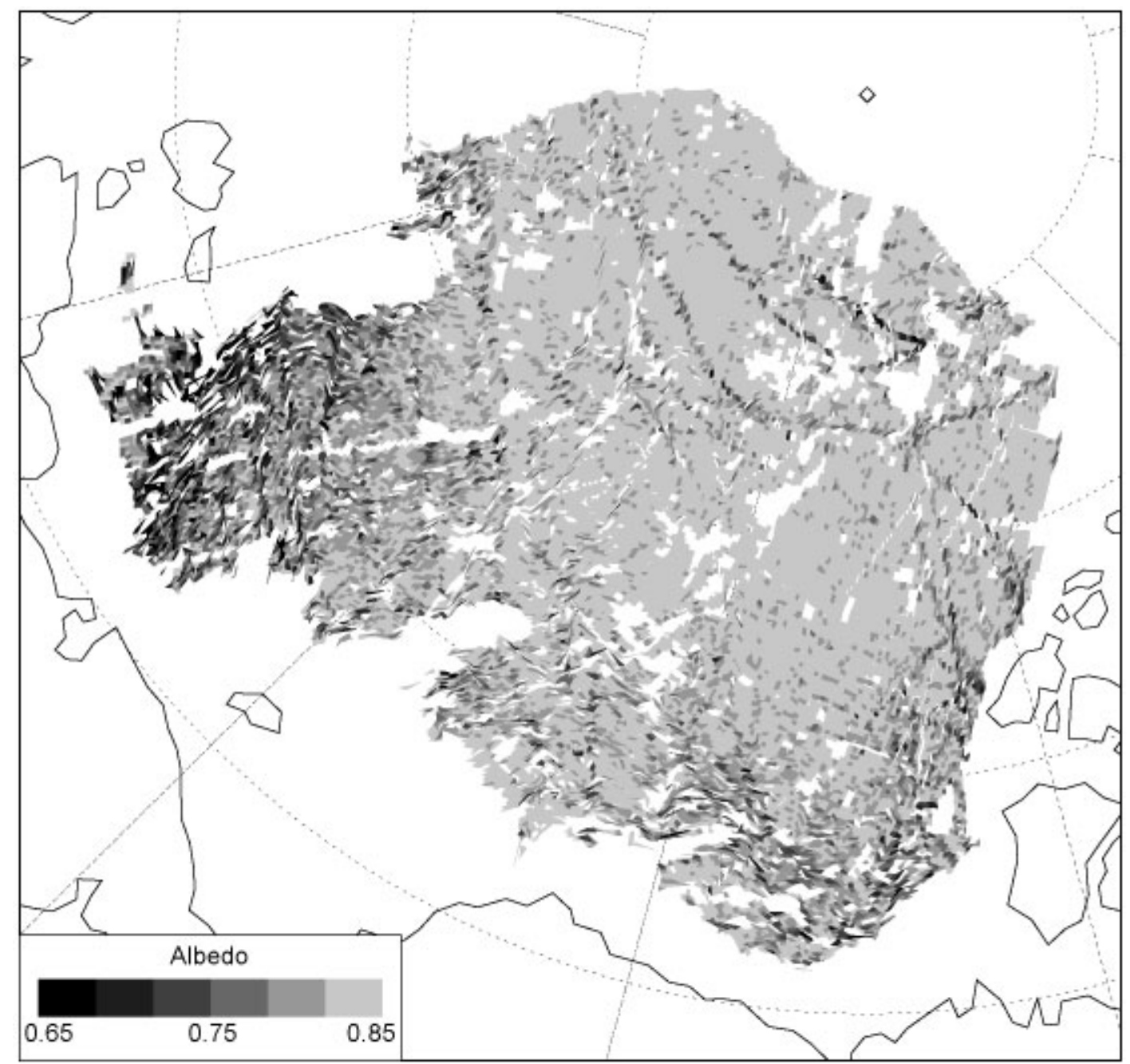

Fig. 3. Map of the mean albedo for each cell, 20 April 1997, showing the spatial extent of the estimates. The positions of the points are the final locations after 160 days of drift; 25000 cells are plotted.

albedo is near 0.82 , the value used in the parameterization for thick, cold snow under clear skies, and the characteristic tail of lower albedos is seen down to values near 0.5.

\section{DISGUSSION AND CONGLUSIONS}

Our technique is sensitive to a number of different aspects of the analysis. The RGPS-based thickness distribution is derived from opening and closing measured at roughly 3 day intervals, and there may be significant deformation that occurs at shorter time intervals. While this source of error may cause an underestimate of the ice production, since an undetected opening event followed by a closing event may produce ice that is not accounted for by the RGPS, it may not significantly alter the albedo estimates, since the albedo is most sensitive to the area of thin ice produced by net opening and not to events of opening followed by closing.

A major potential source of error is the assumed snowaccumulation rate over thin ice. For lack of better information, we have used a climatological accumulation rate based on time of year and location. The effect of snow on thick ice is also uncertain. Observations in the Antarctic (Brandt and others, 1999) indicate that just $1 \mathrm{~cm}$ of snow can sometimes increase the albedo of thick ice from 0.49 (no snow) to 0.81 , a larger change than indicated in the parameterization. In this study, thick ice is always considered to have $>10 \mathrm{~cm}$ of snow, so the albedo for this ice is not sensitive to the snow depth, but the snow cover and albedo of thin ice is more uncertain.

The true accumulation rate depends not only on the occurrence of precipitation but also on the evaporation rate and on the occurrence of blowing snow. The wind can both deposit snow on new ice and scour new snow from the smooth surfaces of young ice. It will also deposit snow around ridges, significantly increasing their albedo. In the model, it is assumed that ridged ice has the same albedo as smooth ice, but more information is needed in this regard. Fortunately, the area of ridged ice $<1 \mathrm{~m}$ thick is small, just $0.4 \%$ of the area vs $5.5 \%$ for smooth ice $<1 \mathrm{~m}$ thick.

The albedo parameterization is the linchpin of the technique, and any additional information about how to formulate it or how accurate it is would aid in minimizing and evaluating the errors. The observations from Surface Heat Budget of the Arctic Ocean (SHEBA), both ground-based and from aircraft, may help in evaluating the parameterization.

The AVHRR-based albedo estimates of Comiso (2001) are one possible source for comparisons with the RGPSbased albedo estimates. His values are monthly mean composites of the channel 1 albedo. For the April 1997 composite, the mean albedo value in the northern part of the current study region is about 0.64 , in contrast to 0.80 found in this 

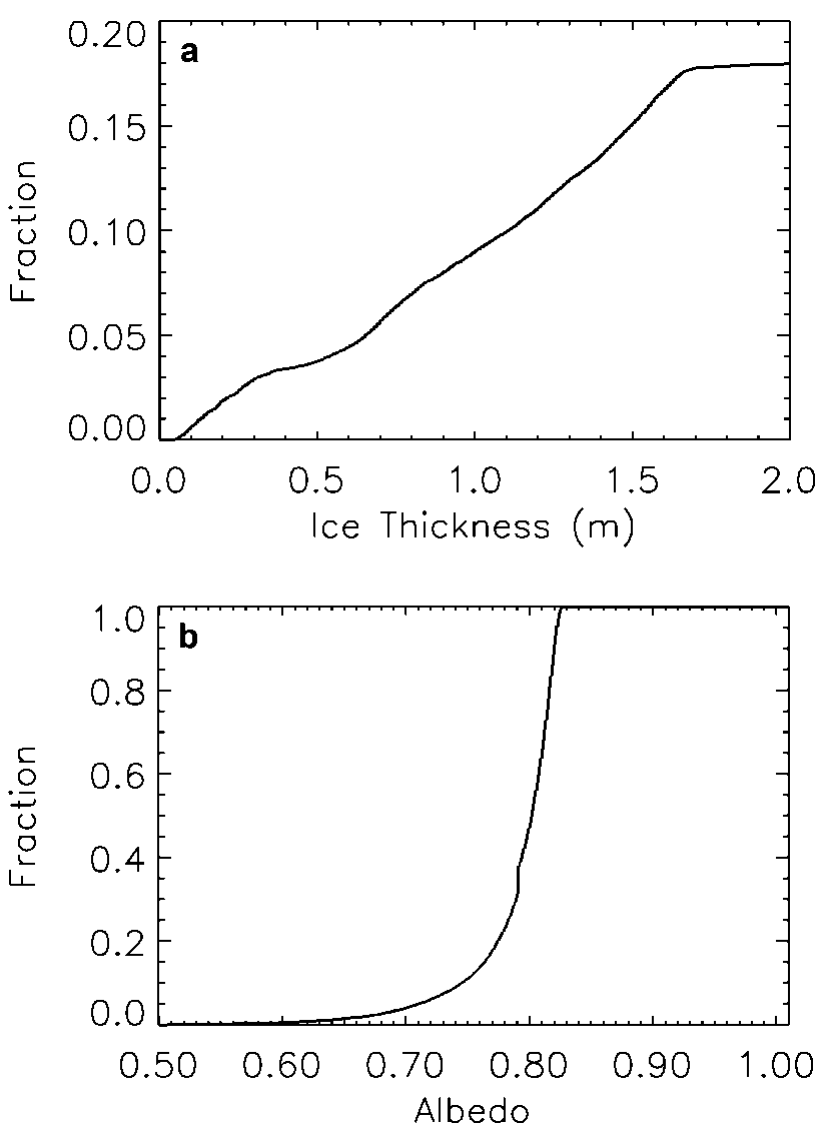

Fig. 4. Cumulative distributions of ( a) the ice thickness of all categories for all cells, and (b) the mean albedo of the $10 \mathrm{~km}$ cells. The thickness distribution is of both the smooth and the ridged ice categories but does not include multi-year ice, which accounts for about $82 \%$ of the area. The mean albedo includes the multi-year ice and is for clear skies with a solar zenith angle of $70^{\circ}$.

study. The fact that his AVHRR-based values are for channel 1 only and are not broadband values may explain some of the difference.

It is possible to extend this technique to the summer months and to improve the estimates of ice thickness by using a more complete dynamic/thermodynamic ice model that is driven by air temperature, winds and satellitederived downwelling radiative fluxes as well as by the RGPS ice-deformation measurements. The model would use dataassimilation methods to include the RGPS ice-motion and -deformation information and could have more realistic ridging redistribution procedures (e.g. Thorndike and others, 1975; Babko and others, in press) in order to obtain improved estimates of the ice-thickness distribution and hence improved estimates of the surface albedo. Such a model that also assimilates ice-concentration measurements would provide a more complete picture, in time and space, of the surface albedo and of the surface energy balance. During the summer months, the most critical parameters in determining the albedo are the fraction of open water and coverage and depth of melt ponds. Thus, accurate methods of predicting melt-pond characteristics and predicting or measuring the fraction of open water are needed to obtain accurate estimates of the summer albedo.
In conclusion, the RGPS represents a first opportunity to obtain relatively high-resolution and high-accuracy basin-wide estimates of the deformation of the ice cover, and we have shown how these measurements can be exploited to obtain estimates of the surface albedo.

\section{ACKNOWLEDGEMENTS}

I would like to thank D. A. Rothrock for suggesting this line of research, R. Kwok for providing the RGPS data and advice on their use, and H. L. Stern for helpful comments on the manuscript. Thanks also to the two reviewers, S. G. Warren and D. K. Perovich, and to the editor, R. Massom, for their helpful comments. The RGPS datasets are produced by the Polar Remote Sensing Group at the Jet Propulsion Laboratory, Pasadena, CA. This work was supported by NASA grant NAG5-4175.

\section{REFERENGES}

Allison, I., R. E. Brandt and S. G. Warren. 1993. East Antarctic sea ice: albedo, thickness distribution, and snow cover. F. Geophys. Res., 98(C7), $12,417-12,429$.

Babko, O., D. A. Rothrock and G. A. Maykut. In press. The role of rafting in the mechanical redistribution of sea-ice thickness. 7. Geophys. Res.

Brandt, R. E., C. S. Rossler and S. G. Warren. 1999. Spectral albedo, absorptance, and transmittance of Antarctic sea ice. In Fifth Conference on Polar Meteorology and Oceanography, 10-15 January 1999, Dallas, Texas. Proceedings. Boston, MA, American Meteorological Society, 456-459.

Comiso, J. C. 2001. Satellite-observed variability and trend in sea-ice extent, surface temperature, albedo and clouds in the Arctic. Ann. Glaciol., 33 (see paper in this volume).

Ebert, E. E. and J. A. Curry. 1993. An intermediate one-dimensional thermodynamic sea ice model for investigating ice-atmosphere interactions. $\mathcal{F}$. Geophys. Res., 98(C6), 10,085-10,109.

Grenfell, T. C. and D. K. Perovich. 1984. Spectral albedos of sea ice and incident solar irradiance in the southern Beaufort Sea. 7. Geophys. Res., 89(C3), 3573-3580.

Key, J. and A. J. Schweiger. 1998. Tools for atmospheric radiative transfer: Streamer and FluxNet. Comput. Geosci., 24(5), 443-451.

Kwok, R. 1998. The RADARSATgeophysical processor system. In Tsatsoulis, C. and R. Kwok, eds. Analysis of SAR data of the polar oceans: recent advances. Berlin, etc., Springer-Verlag, 235-257.

Kwok, R., D. A. Rothrock, H. L. Stern and G. F. Cunningham. 1995. Determination of the age distribution of sea ice from Lagrangian observations of ice motion. IEEE Trans. Geosci. Remote Sensing, GE-33(2), 392-400.

Lindsay, R.W. and D. A. Rothrock. 1994. Arctic sea ice albedo from AVHRR. f. Climate, 7(11), 1737-1749.

Maykut, G. A. 1982. Large-scale heat exchange and ice production in the central Arctic. 7. Geophys. Res., 87(C10), 7971-7984.

Maykut, G. A. 1986. The surface heat and mass balance. In Untersteiner, N., ed. Geophysics of sea ice. London, etc., Plenum Press, 395-463. (NATO ASI Series B: Physics 146.)

Rigor, I., R. Colony and S. Martin. 2000. Variations in surface air temperature observations in the Arctic, 1979-1997. J. Climate, 13(5), 896-914.

Robinson, D. A., M. G. Serreze, R. G. Barry, G. Scharfen and G. Kukla. 1992. Large-scale patterns and variability of snowmelt and parameterized surface albedo in the Arctic Basin. f. Climate, 5(10), 1109-1119.

Rossow, W. B. and R. A. Schiffer. 1991. ISCCP cloud data products. Bull. Am. Meteorol. Soc., 72(1), 2-20.

Schweiger, A.J., M. C. Serreze and J. R. Key. 1993. Arctic sea ice albedo: a comparison of two satellite-derived data sets. Geophys. Res. Lett., $20(1), 41-44$.

Shine, K. P. and A. Henderson-Sellers. 1985. The sensitivity of a thermodynamic sea ice model to changes in surface albedo parameterization. 7. Geophys. Res., 90 (D1), 2243-2250.

Thorndike, A. S., D. A. Rothrock, G. A. Maykut and R. Colony. 1975. The thickness distribution of sea ice. 7. Geophys. Res., 80 (33), 4501-4513.

Warren, S.G. and 6 others. 1999. Snow depth on Arctic sea ice. F. Climate, 12(6), 1814-1829. 